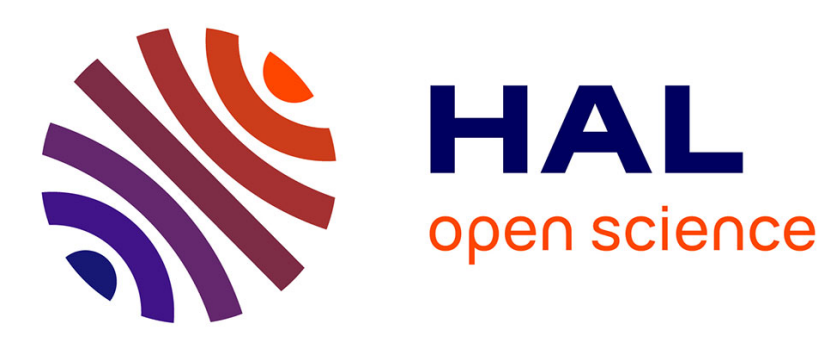

\title{
Solitary Waves Observed By Cluster In the Solar Wind
}

\author{
M. Fraenz, T. S. Horbury, Vincent Génot, O. Moullard, Henri Rème, I.
}

Dandouras, A. N. Fazakerley, A. Korth, F. Frutos-Alfaro

\section{To cite this version:}

M. Fraenz, T. S. Horbury, Vincent Génot, O. Moullard, Henri Rème, et al.. Solitary Waves Observed By Cluster In the Solar Wind. AIP Conference Proceedings, 2003, 679, pp.562. 10.1063/1.1618659 . hal-00306237

\section{HAL Id: hal-00306237 \\ https://hal.science/hal-00306237}

Submitted on 21 Oct 2008

HAL is a multi-disciplinary open access archive for the deposit and dissemination of scientific research documents, whether they are published or not. The documents may come from teaching and research institutions in France or abroad, or from public or private research centers.
L'archive ouverte pluridisciplinaire HAL, est destinée au dépôt et à la diffusion de documents scientifiques de niveau recherche, publiés ou non, émanant des établissements d'enseignement et de recherche français ou étrangers, des laboratoires publics ou privés. 


\title{
Solitary Waves Observed By Cluster In the Solar Wind
}

\author{
M.Fränz ${ }^{*}$, T.S.Horbury ${ }^{\dagger}$, V.Génot**, O.Moullard ${ }^{\ddagger}$, H.Rème, I.Dandouras ${ }^{\S}$, \\ A.N.Fazakerley ${ }^{\mathbb{I l}}$, A.Korth* and F.Frutos-Alfaro* \\ ${ }^{*}$ MPI für Aeronomie,D-37191 Katlenburg-Lindau, D; Email: fraenz @ I inmpi .mpg. de \\ $\dagger$ Imperial College,London SW7 2BW,UK \\ ${ }^{* *}$ Queen Mary, Univ.London,London E1 4NS,UK \\ ${ }^{\ddagger}$ ESTEC, 2200AG Noordwijk, NL \\ ${ }^{\S}$ CESR,F-31028 Toulouse cedex 4,F \\ "MSSL, Dorking RH5 6NT, UK
}

\begin{abstract}
Short dropouts of the magnetic field intensity have been frequently observed in the solar wind on interplanetary spacecraft. But so far it could not be established whether these are caused by kinetic instabilities or whether they can be described as solitary MHD waves. The multi-satellite observations of the Cluster-mission allow for the first time to measure proton and electron distributions with a sufficient temporal and spatial resolution to tackle this question. We use measurements by the FGM magnetometer, the CIS ion spectrometer, the PEACE electron instrument and the Whisper plasma wave instrument to investigate the role of protons, heavy ions and electrons for the stability of the structures. We also use the 4-satellite observations of the Cluster magnetic field instrument to determine the proper motion of these structures relative to the solar wind. The presence of foreshock waves close to the Earth bowshock strongly limits the event selection. In the current paper we discuss a $10 \mathrm{~s}$ linear wave without sufficient particle data resolution and a 4 min wave for which particle distributions are available. The larger wave shows that the stability of the structure might be caused by changes in the thermal electron distributions while proton and $\alpha$ distributions are unaffected.
\end{abstract}

\section{MAGNETIC HOLES - SOLITONS?}

Magnetic field dropouts are commonly observed in planetary magnetosheaths in high plasma $\beta$ conditions. These observations are usually explained by mirror mode instabilities characterized by anisotropic proton distributions $[1,2]$. Ulysses data have shown that field dropouts are also common in the solar wind [3]. But it could not be established that these favorably occur in high plasma $\beta$ conditions and are correlated with proton temperature anisotropies [4]. Recently it was suggested that these dropouts can be explained as solitary MHD waves in MHD models with additional friction [5] or bi-ion plasmas [6]. The frequency of field dropouts in the interplanetary field suggests that they can significantly affect energetic ion diffusion [7]. The existence of MHD solitary waves in astrophysical plasmas would be of high interest for MHD theory and would have impact on the occurrence of plasma instabilities.

\section{CLUSTER OBSERVATIONS}

4-spacecraft observations in the solar wind allow for the first time to determine proper speed and spatial structure of magnetic holes in the solar wind. For that purpose a working group has been established involving the Cluster ion and electron instruments (CIS, PEACE) and the magnetic and electric field investigations (FGM, EFW, STAFF, WHI) ${ }^{1}$. This paper concentrates on preliminary observations of the CIS ion spectrometer[8], FGM magnetometer[9], the PEACE electron spectrometer [10] and the WHI wave spectrometer[11]. The Cluster spacecraft encountered the solar wind for several hours on each orbit for the periods January to June 2001 and again from January 2002. We first determined the solar wind periods by eye using the CIS proton energy spectra. Then we did an automatic search through those periods looking for field drops of more than $3 \sigma$ in 4 min windows using a $12 \mathrm{~s}$ sliding average of the $4 \mathrm{~s}$ field data similar to the method used previously for Ulysses

1 See: http://www.linmpi.mpg.de/ fraenz/magholes 


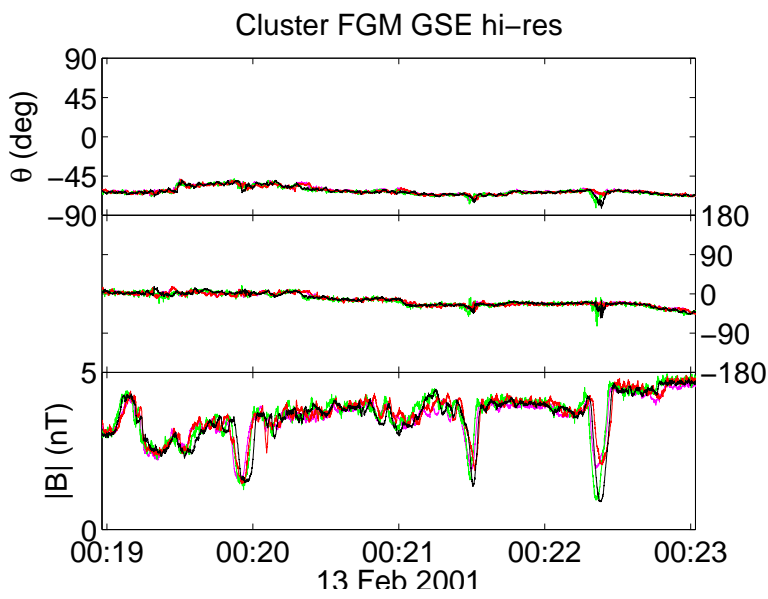

FIGURE 1. First set of solitary linear waves observed by Cluster upstream of the Earth bowshock at 19.5 Re 12.6 MLT on 13 Feb 2001. Shown are magnetic field GSE polar and azimuth angles and total magnitude at 22 vectors/s for all 4 S/C (black,red,green,magenta). The extension of the structures in time is about $10 \mathrm{~s}$ corresponding to a size of $5000 \mathrm{~km}$ at a solar wind speed of $V_{p}=450 \mathrm{~km} / \mathrm{s}$.

data[4]. This gave us a list of 14 events for data until 15 Feb 2002. The main problem was then to exclude events related to the proximity of the Earth bowshock, specifically fore-shock cavities as discussed by [12]. It turned out that the only safe method to do this is to compare with data from an upstream satellite. From the 14 events there was one left which was also visible in ACE key parameters and not associated with a field reversal. This is the second event discussed below.

\section{SELECTED EVENTS}

The first set of solitary waves (Fig. 1) observed by Cluster on 13 Feb 2001 is shown here because of its obvious wave form. It was not discovered by an automatic search. Unfortunately the size of only $10 \mathrm{~s}(5000 \mathrm{~km})$ is too small to get any reliable particle measurements from within the waves. Also the wave is not visible in the public (16s) ACE data sets. This makes it difficult to exclude the proximity of the Earth bow shock as a possible source of these waves. Plasma conditions in the surrounding plasma were: $n_{p}=12 \mathrm{~cm}^{-3}, n_{\alpha}=0.9 \mathrm{~cm}^{-3}$, $T_{p}=0.2 \mathrm{MK}, v_{p_{G S E}}=(-450,20,-10) \mathrm{km} / \mathrm{s}$. This corresponds to a ion thermal pressure of $P_{i}=0.04 \mathrm{nPa}$ or $\beta_{i}=$ 4.4 and an Alfv́en speed $v_{A}=27 \mathrm{~km} / \mathrm{s}$ for a $5 \mathrm{nT}$ field.

The motion of 3 structure boundaries in the plasma rest frame has been determined from the 4-point measurement to be between $7-14 \mathrm{~km} / \mathrm{s}$. This is still in agreement with convection with the solar wind - taking into account the error in calculation.
The large wave (Fig. 2, bottom) observed on 22 Feb 2001 has a temporal extent of 4 min -indicated by the black frame - corresponding to a size of about 100000 $\mathrm{km}$. Data in Fig. 2 have a time resolution of $4 \mathrm{~s}$ if not stated otherwise. The event is also seen in $16 \mathrm{~s}$ ACE magnetic field data (bottom panel) $210 \mathrm{RE}$ upstream of Cluster. Thus it is clearly of solar wind origin. Also the time delay of $50 \mathrm{~min}$ between ACE and Cluster proves the stability of the structure. Though the holes are not linear (panel 8,9), there is no indication that the event forms a magnetic cloud, nor that it is associated with a current sheet crossing since there is no field reversal. The large size allows detailed particle measurements within the structure. There is no strong signature in thermal proton moments (panel 5,7), also no change in $\alpha$ densities(panel $6)$. The proton and $\alpha$ moments with 4 s time resolution are onboard moments . while moments with 16 s resolution (red traces and panel 7) are calculated on ground from the 3D distributions. The $16 \mathrm{~s}$ proton velocity distribution (Fig. 3) shows no distortion associated with the field dropouts. The only strong signal we can observe so far are in the thermal electron data (panel 1,2): Electron temperature decreases are observed associated with the field dropouts on SC2 (panel 1). A similar behavior is not visible on $\mathrm{C} 1$ and $\mathrm{C} 4$ since PEACE data cannot be corrected for spacecraft potential - the data in panel 1 can only be used qualitatively. Also it cannot be determined whether the parallel temperature dropouts correspond to a change in anisotropy. Electron densities from WHI in panel 2 may be used quantitatively and show that electron density variations are much stronger than proton density variations but correlation with the field dropouts are complex. We have not yet analyzed electric field data for this event. Plasma conditions in the surrounding plasma where: $n_{p}=6 \mathrm{~cm}^{-3}, n_{\alpha}=0.5 \mathrm{~cm}^{-3}$, $T_{p}=0.1 \mathrm{MK}, v_{p_{G S E}}=(-340,20,-30) \mathrm{km} / \mathrm{s}$, which corresponds to $P_{i}=0.01 \mathrm{nPa}, \beta_{i}=1.1$ and $v_{A}=38 \mathrm{~km} / \mathrm{s}$. Thus this event does not occur in high $\beta$ conditions.

4 -point measurements of the motion of 4 structure boundaries results in a speed of $5 \mathrm{~km} / \mathrm{s}$ for two boundaries and $30 \mathrm{~km} / \mathrm{s}$ for the other two. While the second value is closer to the Alfvén speed we must emphasize that the precision of the determination is currently not good enough to draw strong conclusions from that. We hope to improve on these measurements by considering the timing measurements relative to the ACE spacecraft.

The observations suggest that the electrons play a crucial role in the description of these waves. In contrast to magnetospheric electron holes [13] there are no clear density drops, but probably temperature anisotropies. An explanation by electron mirror modes might be possible (R.A. Treumann, personal comm.). 


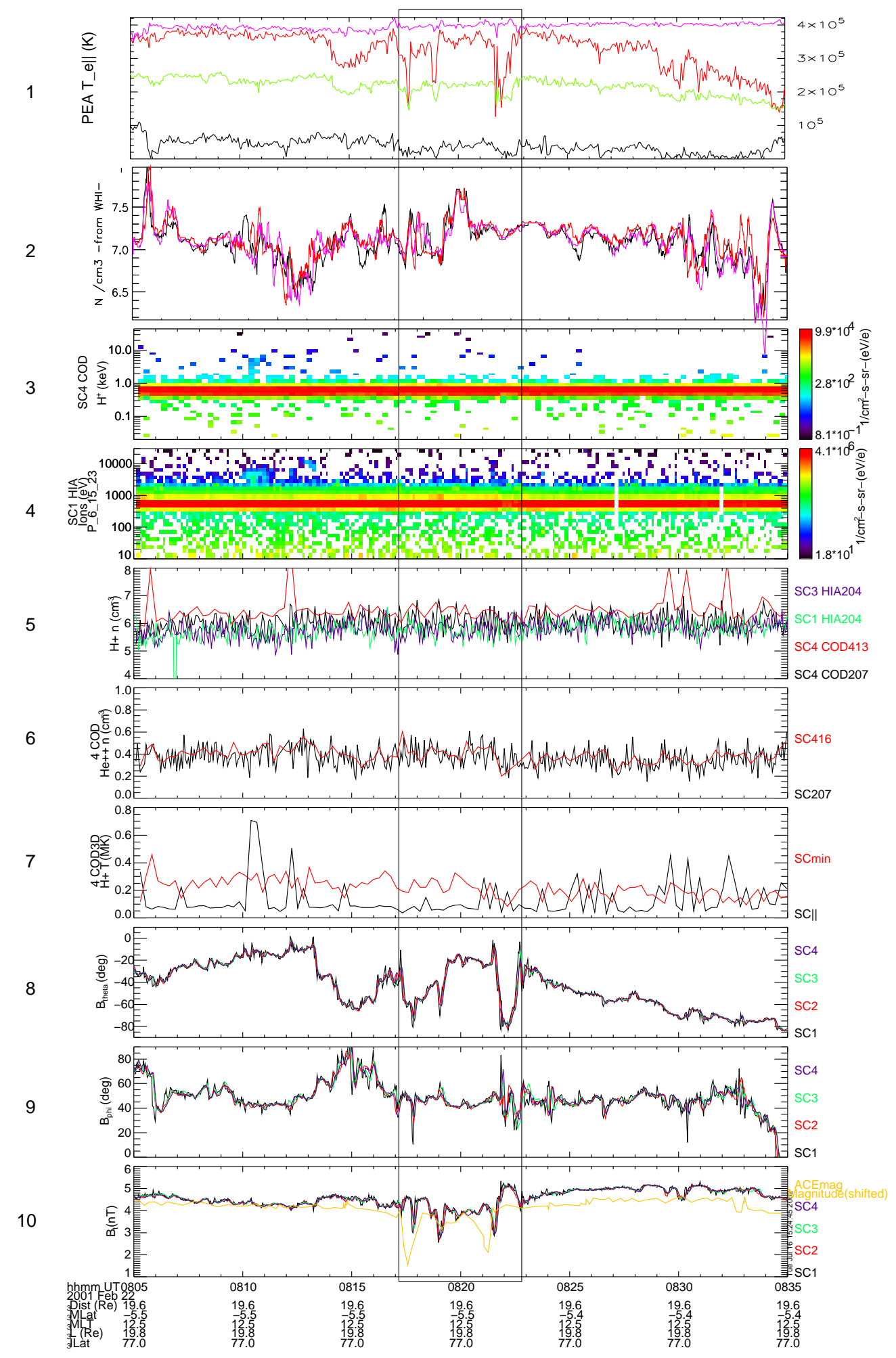

FIGURE 2. Large wave observed by ACE and Cluster on $22 \mathrm{Feb} 2001$ at $19.6 \mathrm{RE}$ and MLT=12.5 h. The panels show from top to bottom: (1)Parallel electron temperature (PEACE) for C1(black), C2(red), C3(green), C4(magenta), not corrected for SC-potential; (2)Electron density (WHI) for C1,C2,C4; 16s proton spectra of the CIS C1 CODIF(3) and HIA(4) sensors, respective onboard proton densities(5), the ground(16 s) and onboard(4s) $\alpha$ density on $\mathrm{C} 4(6)$, ground(16s) parallel and perpendicular temperature(7); magnetic field GSE theta(8), phi(9) angles and magnitude(10) for all 4 SC. The bottom panel shows also 16 s magnetic field magnitude at the ACE spacecraft shifted in time by about $50 \mathrm{~min}$, using the ACE distance and solar wind velocity (orange).

Solitary Waves

Observed By Cluster In the Solar Wind

Solar Wind 10, SIII 57 


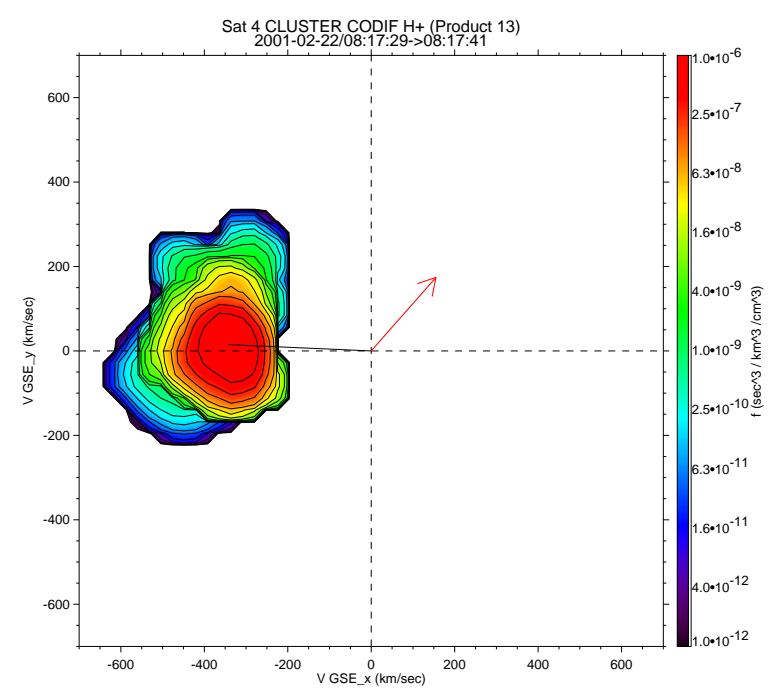

FIGURE 3. CIS Proton Velocity Distribution passing through a magnetic depression at 20010222T08:17, taken by the CODIF sensor on C4 projected onto the GSE XY-plane. The plot also contains the magnetic field vector projection (red).

\section{CONCLUSIONS}

For the detection of solar wind magnetic holes with Cluster it is very advisable to correlate data with an upstream spacecraft. This sets a lower limit of about $30 \mathrm{~s}$ on the size of detectable structures. Also proton velocity distributions on Cluster are only obtained with $16 \mathrm{~s}$ time resolution at $11^{\circ}$ angular resolution in normal telemetry mode. The comparison with ACE data allows to clearly identify holes of solar wind origin. Nevertheless we show one event which has a smooth solitary and linear wave form and might be described as a MHD soliton. It is the only event of this type discovered in Cluster data for 2001. But the size of only $8 \mathrm{~s}$ does not allow a more detailed particle analysis. The $4 \mathrm{~s}$ onboard moments do not show significant changes.

A systematic search for events larger than 30 s visible at ACE and Cluster resulted in only one event without field reversal for which particle distributions are available. This event does neither show significant proton temperature anisotropies indicative of proton mirror modes, nor density increases or velocity vector sweeps expected for Hall-MHD solitons. The signature in electrons - specifically temperature dropouts and density variations are much stronger. This agrees with the observation that magnetic holes observed by Ulysses are often associated with Langmuir waves[14]. Determination of proper speed is difficult at Cluster separations of $\sim 600$ $\mathrm{km}$. Both events discussed show proper speeds in agreement with convection with solar wind. For the second event we hope to improve the analysis using higher res- olution data from ACE. Another large hole observed by Ampte and ISEE1 upstream of the Earth bowshock [15] was also convected with the solar wind and has some features in common with the event discussed here.

We are confident that the combination of Cluster ion, field and wave data at larger spacecraft separations in the later parts of the mission will elucidate the physics of magnetic holes in the solar wind.

\section{ACKNOWLEDGMENTS}

We are very grateful for the support from the Cluster community and specifically the CIS team and the working group on solitary waves. We acknowledge the provision of the ACE MAG (N. Ness at Bartol) and SWEPAM (D. McComas at LANL) data through the CDAWeb system and the support by K-H. Fornaçon and K-H. Glaßmeier (Univ. Braunschweig). T. S. Horbury and V. Génot are supported by PPARC (UK) fellowships.

\section{REFERENCES}

1. Tsurutani, B., Smith, E., Andersen, R., Ogilvie, K., Scudder, J., Baker, D., and Bame, S., J. Geophys. Res., 87, 6060-6072 (1982).

2. Baumgärtel, K., Planet. Space Sci., 49, 1239-1247 (2001).

3. Winterhalter, D., Neugebauer, M., Goldstein, B., and Smith, E., J. Geophys. Res., 99, 23,371-23,381 (1994).

4. Fränz, M., Burgess, D., and Horbury, T., J. Geophys. Res., 105, 12725-12732 (2000).

5. Baumgärtel, K., J. Geophys. Res., 104, 28295-28308 (1999).

6. McKenzie, J., J. Plasma Phys., 65, 181-195 (2001).

7. Tsurutani, B., Lakhina, G., Winterhalter, D., Arballo, J., Galvan, C., and Sakurai, R., Nonlinear Process Geophys., 6, 235-242 (1999).

8. Rème, H., Aoustin, C., Bosqued, M., Dandouras, I., and the CIS-team, Ann. Geophys., 19, 1303-1354 (2001).

9. Balogh, A., Carr, C., Acuña, M., Dunlop, M., and the FGM-team, Ann. Geophys., 19, 1207-1217 (2001).

10. Johnstone, A., Alsop, C., Burge, S., Carter, P., and the PEACE-team, Space Sci. Rev., 79, 351-398 (1997).

11. Decreau, P., Fergeau, P., Krasnoselskikh, V., and the Whisper-team, Ann. Geophys., 19, 1241-1258 (2001).

12. Sibeck, D., Decker, R., Mitchell, D., Lazarus, A., Lepping, R., and Szabo, A., J. Geophys. Res., 106, 21675-21688 (2001).

13. Chen, J., and Parks, G., Nonlinear Process Geophys., 9, 111-119 (2002).

14. Lin, N., Kellogg, P. J., Macdowall, R. J., Balogh, A., Forsyth, R. J., Phillips, J. L., Buttighofer, A., and Pick, M., Geophys. Res. Lett., 22, 3417-3420 (1995).

15. Chisham, G., Schwartz, S. J., Burgess, D., Bale, S. D., Dunlop, M. W., and Russel, C. T., J. Geophys. Res., 105, 2325-2335 (2000). 